University of Wollongong

Research Online

Faculty of Social Sciences - Papers (Archive) Faculty of Arts, Social Sciences \& Humanities

$1-1-2016$

\title{
Mindfulness and emotional regulation as sequential mediators in the relationship between attachment security and depression
}

Judith A. Pickard

University of Wollongong, jap988@uowmail.edu.au

Peter Caputi

University of Wollongong, pcaputi@uow.edu.au

Brin F. S Grenyer

University of Wollongong, grenyer@uow.edu.au

Follow this and additional works at: https://ro.uow.edu.au/sspapers

Part of the Education Commons, and the Social and Behavioral Sciences Commons

Research Online is the open access institutional repository for the University of Wollongong. For further information contact the UOW Library: research-pubs@uow.edu.au 


\title{
Mindfulness and emotional regulation as sequential mediators in the relationship between attachment security and depression
}

\begin{abstract}
Depression is a significant global health issue that has previously been associated with negative early care experiences and insecure attachment styles. This has led to much interest in identifying variables that may interrupt this relationship and prevent detrimental personal, social and economic outcomes. Recent research has indicated associations between the two seemingly distinct constructs of secure attachment and mindfulness, with similar positive outcomes. One hundred and forty eight participants completed an online survey exploring a possible sequential cognitive processing model, which predicted that higher levels of mindfulness and then emotional regulation would mediate the relationship between attachment and depression. Full mediation was found in regards to secure, preoccupied and dismissive attachment, whereas partial mediation was identified in the case of fearful attachment. The results support the possibility of an alternative cognitive processing pathway that may interrupt the association between negative early care experiences and concomitant negative mental health outcomes. Further exploration of this relationship is indicated.
\end{abstract}

\section{Keywords}

security, sequential, depression, mediators, relationship, between, attachment, mindfulness, emotional, regulation

\section{Disciplines}

Education | Social and Behavioral Sciences

\section{Publication Details}

Pickard, J. A., Caputi, P. \& Grenyer, B. F. S. (2016). Mindfulness and emotional regulation as sequential mediators in the relationship between attachment security and depression. Personality and Individual Differences, 99 179-183. 
Mindfulness and Emotional Regulation as sequential mediators in the relationship between attachment security and depression

\begin{abstract}
Depression is a significant global health issue that has previously been associated with negative early care experiences and insecure attachment styles. This has led to much interest in identifying variables that may interrupt this relationship and prevent detrimental personal, social and economic outcomes. Recent research has indicated associations between the two seemingly distinct constructs of secure attachment and mindfulness, with similar positive outcomes. One hundred and forty eight participants completed an online survey exploring a possible sequential cognitive processing model, which predicted that higher levels of mindfulness and then emotional regulation would mediate the relationship between attachment and depression. Full mediation was found in regards to secure, preoccupied and dismissive attachment, whereas partial mediation was identified in the case of fearful attachment. The results support the possibility of an alternative cognitive processing pathway that may interrupt the association between negative early care experiences and concomitant negative mental health outcomes. Further exploration of this relationship is indicated.
\end{abstract}

Key words: mindfulness, emotional regulation, attachment theory, depression, sequential mediation model. 
Mindfulness and Emotional Regulation as sequential mediators in the relationship between attachment security and depression

\section{Introduction}

Depression is a significant global health issue affecting quality of life, mortality and morbidity (Kessler \& Bromet, 2013). By 2020, it is predicted to represent approximately 15 percent of the global burden of disease (Murray \& Lopez, 1996). Previous research has identified a well-established link between attachment styles and developmental outcomes, including mental health, e.g. depression; physical health and social outcomes (Bifulco et al., 2004; Bowlby, 1980; Schore, 2001; Sroufe, 2005; Sroufe, Egeland, Carlson, \& Collins, 2005a). According to Bowlby (1980), depression is associated with a perceived helplessness in developing and sustaining relationships, reportedly formulated from negative early care experiences instrumental in the development of internal working models that see one as unlovable and unworthy (Cummings \& Cicchetti, 1990). Consistent with Bowlby (1980), Roepke and Seligman (2015) report negative prospections, i.e., mental representations of future scenarios, similarly underpinned by a pessimistic template, as the primary causal variable in the development and maintenance of depression. These perspectives match Beck's influential discoveries about cognitive distortions (Beck, 1963). The effect of preconceived beliefs on the aetiology of depression clearly indicates the importance of contrary mental activities such as current moment awareness, to allow an individual to experience self as an effective agent of change and reduce the incidence of depression. Increased mindfulness has previously been proposed to result in improved social functioning through a reduction in defensive responding on cognitive, emotional and behavioural levels (Brown, Ryan, \& Creswell, 2008; Carson, Carson, Gil, \& Baucom, 2004). The current study explores the possible role of mindfulness and emotional regulation as sequential mediators in the cognitive process between attachment and depression.

Attachment styles were initially differentiated by Ainsworth, Blehar, Waters \& Wall (1978) identifying distinct categories of relationship between infants and their primary caregiver. The availability and accessibility of a sensitive caregiver was associated with a secure 
Mindfulness and Emotional Regulation as sequential mediators in the relationship between attachment security and depression

attachment style, typically characterised by effective emotional regulation. Conversely, the absence of a sensitive caregiver reportedly results in an insecure attachment style associated with largely ineffective strategies for need fulfilment. The insecure attachment styles are differentiated into three categories: insecure-ambivalent, insecure-avoidant and insecure-disorganised attachment styles (Ainsworth, et al., 1978; Main \& Cassidy, 1988) and are associated with poorer mental health outcomes, including depression (Cummings \& Cicchetti, 1990; Sroufe, 2005). Adult classifications, i.e. secure, preoccupied, dismissive and fearful, paralleling those identified in childhood, support the continuity of attachment history (Bartholomew \& Horowitz, 1991). Further, preoccupied and fearful attachment styles have been associated with a higher propensity for postpartum depression, mediated by low selfesteem and self-critical thoughts (Lee \& Koo, 2015). The authors attribute this association to the 'negative self' model characteristic of these attachment styles (Bartholomew \& Horowitz, 1991). Conversely, a dismissive style, associated with a 'positive self' model was not found to be significantly related to depression (Reis \& Grenyer, 2004). The significant impact on mental wellbeing, health and social outcomes behoves us to identify variables that may alter attachment styles and/or their impact.

Internal working models reportedly provide a set of rules for processing attachment related information (Bowlby, 1973; Bretherton \& Mulholland, 2008; Dykas \& Cassidy, 2011). Bowlby (1980) referred to the "defensive exclusion" of potentially painful information. Essentially, this requires the individual to filter out such information from further processing. This strategy is seemingly less utilised by an individual with a secure attachment history, allowing for more open processing. Furthermore, secure individuals are reported to process non-attachment related information in a positively biased manner and insecure individuals, with a negative bias (Dykas \& Cassidy, 2011).

Essentially, the internal working models provide expectation for future outcomes (Bretherton \& Mulholland, 2008). An individual with a secure history tends to anticipate being capable in 
Mindfulness and Emotional Regulation as sequential mediators in the relationship between attachment security and depression

eliciting care and hence, confident in tolerating and recovering from difficult emotions. In their review of attachment and social processing, Dykas and Cassidy (2011) identify competence as including the ability to acknowledge, accept and recover from distressing emotions; a process consistent with mindful awareness and emotional regulation; supportive of literature identifying commonality between the constructs: secure attachment and mindfulness (Goodall, Trejnowska, \& Darling, 2012; Siegel, 2007).

To interrupt the relationship between attachment styles and depression it is seemingly important to allow for the incorporation of new information regarding current context, which may then afford new experiences of lovability and worthiness. Automatic processing has been referred to as a "top down" approach, where schemas, memories, cognitions and emotions interpret and influence understanding of sensations and hence, shape experience, conversely mindfulness is the maintenance of awareness, to take in and process information as it is, in the current context (Siegel, 2007). It implies an open processing, without bias, affording a flexible response and deviation from organised behavioural patterns (Brown, Ryan, \& Creswell, 2007). Kabat-Zinn (2003) indicates the importance of a curious mind in allowing one to process new experiences openly, a stance contrary to that engaged in when connected to pre-conceptualisations. This allows for the incorporation of novel information into schemas or working models, which may alter attachment style or limit their influence. Further, a more contextually appropriate response may provide new information regarding self. Behavioural manifestation of this is perhaps witnessed in the secure young child through exploratory behaviour, which occurs through the experience of safety, allowing deactivation of the attachment system (Cassidy, 2008).

Siegel (2007) highlights the overlap of outcome measures related to attachment security and mindfulness, specifically referring to the prefrontal cortex and its role in modulating fear, response flexibility, self-regulation, attunement, empathy and emotional balance. This is supported by a British online survey (Goodall, et al., 2012) reporting a potential bidirectional 
Mindfulness and Emotional Regulation as sequential mediators in the relationship between attachment security and depression

relationship between mindfulness and attachment security, suggesting that increased mindfulness skills could reduce the behaviours more characteristic of insecure attachment styles. Further they indicate a conceptual overlap between aspects of dispositional mindfulness and emotional regulation, namely; the awareness of internal experiences and acceptance of emotional response. The authors highlight the importance of emotional awareness in reducing the cognitive bias common to a more automatic processing style. A further study by Pepping, Davis and Donovan (2013) reported that the relationship between mindfulness and attachment security was fully mediated by emotional regulation difficulties. This is consistent with the underlying premise that a secure attachment results from the internalisation of soothing care experiences and facilitates the development of self-regulation strategies (Snyder, Shapiro, \& Treleaven, 2012; Sroufe, et al., 2005a; Thorberg \& Lyvers, 2010). Following the Minnesota longitudinal study, Sroufe (2005) reports infant attachment as critical to the development of emotional regulation and other functional capacities.

\section{Current study}

Mindfulness has been associated with a range of positive emotional and social variables, including wellbeing (Baker, Huxley, Dennis, Islam, \& Russell, 2015; Mitchell \& Heads, 2015), relationship satisfaction (Jones, Welton, Oliver, \& Thoburn, 2011) and a decrease in emotional distress factors, e.g. depression and anxiety (Pepping, O'Donovan, ZimmerGembeck, \& Hanisch, 2014); findings that share similarity with a secure attachment history. Mindfulness is proposed to provide opportunity for perspective and space between thoughts, emotions and possible behavioural choices. Further it allows one to see that an emotion will pass, facilitating tolerance (Snyder, et al., 2012). This understanding of mindful awareness is akin to the full processing of social information and self-regulation proposed for securely attached individuals (Bowlby, 1980; Dykas \& Cassidy, 2011). Given the commonality shared between the two constructs, mindfulness and secure attachment, and their relationship to emotional regulation, the following study seeks to explore a possible sequential mediation 
Mindfulness and Emotional Regulation as sequential mediators in the relationship between attachment security and depression

model of mindfulness and emotional regulation in the relationship between attachment style and depression. It is proposed here that the ability to disengage from previous associations allows for a less conceptually reactive response thereby reducing negative prospections and ameliorating psychological distress, namely, depression. It is hypothesised that mindfulness and then emotional regulation has an indirect effect on the relationship between attachment and depression.

\section{Method}

\subsection{Participants}

One hundred and fifty-one participants ( 111 female and 40 males ranging in age from 18 to 52 years, $M=21.28, S D=5.89$ ), enrolled in a first year psychology course at a regional university completed an online survey to receive credit for their course requirements. The Depression Anxiety Stress Scale (Lovibond \& Lovibond, 1995) mean scores for the total sample revealed moderate depression (18.68, S.D. 9.45), severe anxiety (16.25, S.D. 7.65), and moderate stress $(20.18$, S.D. 10.12). This is consistent with studies reporting a two-fold increase in prevalence of distress amongst university students compared with the general population; representing a high risk population (Stallman, 2010). Of the 151 participants, 61 (40.4\%) selected a secure attachment style as the category of "best fit" on the Relationship Questionnaire (Bartholomew \& Horowitz, 1991), 29 (19.2\%) preoccupied, 40 (26.5\%) fearful and $21(13.9 \%)$ as dismissive.

\subsection{Measures}

2.2.1 Five facets Mindfulness Questionnaire (FFMQ), (Baer, Smith, Hopkins, Krietemeyer, \& Toney, 2006) - The FFMQ is a 39 item scale measuring five identifiable facets of mindfulness. They include: (i) Non reactivity, (ii) Observing/noticing/attending, (iii) Acting with awareness, (iv) Describing/labelling with words and (v) Non-judging of experience. It is rated on a 5 point Likert-type scale ranging from 1 (never or very rarely true) to 5 (very often or always true). According to Baer et al (2006) the FFMQ demonstrated adequate to good 
Mindfulness and Emotional Regulation as sequential mediators in the relationship between attachment security and depression

internal consistency with alpha values ranging between .75 and 91 with modest correlations between factors.

\subsubsection{Relationship Questionnaire (RQ)(Bartholomew \& Horowitz, 1991)- The continuous} items of the $R Q$ were used to identify attachment style. The $R Q$ consists of four short paragraphs that describe relationship attitudes. Each paragraph is rated on a 7-point Likerttype Scale ranging from 1 (does not describe me at all) to 7 (describes me exactly). For example the preoccupied item states: "I want to be completely emotionally intimate with others, but I often find that others are reluctant to get as close as I would like. I am uncomfortable being without close relationships, but I sometimes worry that others don't value me as much as I value them". Reliability estimates for the RQ scales have been reported for attachment classifications as fair (kappas of approximately .35) and moderate for ratings $(r=.50)$ (Crowell, Fraley, \& Shaver, 2008).

\subsubsection{Difficulty in Emotional Regulation Scale (DERS) (Gratz \& Roemer, 2004) -}

The DERS is a 36-item scale comprised of six factors assessing the different facets of emotional regulation. Each item is rated on a 5-point Likert type scale ranging from 1 (almost never) to 5 (almost always). It generates a total score as well as six factor scores. The six distinct dimensions include: (i) non acceptance of emotional responses, (ii) difficulties in engaging in goal directed behaviour, (iii) impulse control difficulties, (iv) lack of emotional awareness, (v) limited access to emotional regulation strategies, (vi) lack of emotional clarity. Gratz and Roemer (2004) reported the DERS has high internal consistency $(\alpha=.93)$ and Cronbach alpha coefficients of .80 for each subscale. Additionally, the authors state that the scale has good test-retest reliability $\left(\mathrm{p}_{1}=.88\right)$, as well as adequate predictive and construct validity.

\subsubsection{Depression Anxiety Stress Scale (DASS) (Lovibond \& Lovibond, 1995). The DASS is} a 42-item scale measuring levels of depression, anxiety and stress. It provides information 
Mindfulness and Emotional Regulation as sequential mediators in the relationship between attachment security and depression

regarding the experience of emotional disturbance across the three states. Items are scored on a four point Likert scale ranging from 0 (did not apply to me at all) to 3 (applied to me very much, or most of the time) and relates to the preceding week. The DASS 42 is reported to have good reliability across the three scales; with alpha values of: Depression 0.81 ; Anxiety 0.73, Stress; 0.81 (Lovibond \& Lovibond, 1995).

\section{Procedure}

Ethics approval was attained from the Human Research Ethics Committee (Health and Medical Science). Participants were recruited through the university's online research participation website and provided consent prior to completing the online survey. Participants received one credit point following completion of the survey.

\section{Data Preparation and analysis:}

All data was analysed using SPSS 22. Where data was missing on only one variable within a measure for a participant it was replaced using the series mean method in SPSS. Where more than two variables were missing from a measure the participant was not included in the analysis. Three participants failed to adequately complete the DASS and were removed from the study $(n=148)$.

Spearman's correlations were conducted between variables to provide a preliminary confirmation of expected associations. Following, sequential mediation analysis was conducted using PROCESS macro for SPSS (Hayes, 2009). The mediation analyses in this study were conducted separately for each attachment dimensional score. Mindfulness and then emotional regulation were entered in the mediation analysis. Process involves a bootstrapping procedure developing estimates of indirect effects. Hayes (2009) recommends using at least 5000 resamples to generate a $95 \%$ bias corrected confidence interval $(\mathrm{Cl})$. Where the confidence interval does not include zero, the null hypothesis is rejected. Hayes further notes that a variable may play a mediatory or indirect role between two variables, 
Mindfulness and Emotional Regulation as sequential mediators in the relationship between attachment security and depression

which do not initially appear associated. He accounts for the possibility of an indirect effect by observing that the total effect is a sum of many different paths and may include two or more indirect paths working in opposite directions. 
Mindfulness and Emotional Regulation as sequential mediators in the relationship between attachment security and depression

Results:

Table 1. Mean Standard deviations and Spearman Correlations between variables

\begin{tabular}{|c|c|c|c|c|c|c|c|c|c|}
\hline & Mean & SD & 1 & 2 & 3 & 4 & 5 & 6 & 7 \\
\hline 1. Secure & 4.80 & 1.94 & - & & & & & & \\
\hline 2. Preoccupied & 3.88 & 1.98 & -.16 & - & & & & & \\
\hline 3. Dismissive & 3.85 & 1.88 & -.09 & $-.17^{\star}$ & - & & & & \\
\hline 4. Fearful & 4.21 & 1.87 & $-.55^{\star \star}$ & .09 & -.08 & - & & & \\
\hline 5. FFMQ & 122.75 & 19.43 & $.28^{\star \star}$ & $-.34^{* *}$ & .16 & $-.43^{\star *}$ & - & & \\
\hline 6. DERS & 88.28 & 21.92 & $-.27^{\star \star}$ & $.35^{\star *}$ & $-.19^{*}$ & $.48^{* *}$ & $-.80^{\star *}$ & - & . \\
\hline 7. Depression & 18.68 & 9.46 & $-.26^{\star \star}$ & $.37^{* *}$ & -.13 & $.42^{* *}$ & $-.51^{\star *}$ & $.66^{* *}$ & - \\
\hline
\end{tabular}

$N=148,{ }^{*} p<.05,{ }^{* *} p<.01$ 
Mindfulness and Emotional Regulation as sequential mediators in the relationship between attachment security and depression

Descriptive statistics and correlations are provided in Table 1. All correlations were in the predicted direction. Mindfulness was found to have a significant positive association with secure attachment and a negative association with both preoccupied and fearful attachment. Conversely, a significant negative association was found between difficulties in emotional regulation (DERS) and secure attachment whereas DERS was positively associated with all three insecure attachment styles. A significant negative association was noted for depression with both secure attachment and mindfulness, whilst it had a significant positive association with DERS, preoccupied and fearful attachment. A non-significant negative association was noted between depression and dismissive attachment.

Given the high correlations between the FFMQ and DERS further analysis was conducted to ensure they were in fact separate constructs contributing to the model. The Non acceptance and Awareness factors of the DERS, which appear to share similarity with the FFMQ were removed and the mediation analysis conducted again (Pepping, et al., 2014). The pattern of results remained unchanged indicating both variables contributed to the sequential mediational model. 
Mindfulness and Emotional Regulation as sequential mediators in the relationship between attachment security and depression

Figure 1. Model of mindfulness and emotional regulation as sequential mediators between attachment style and depression

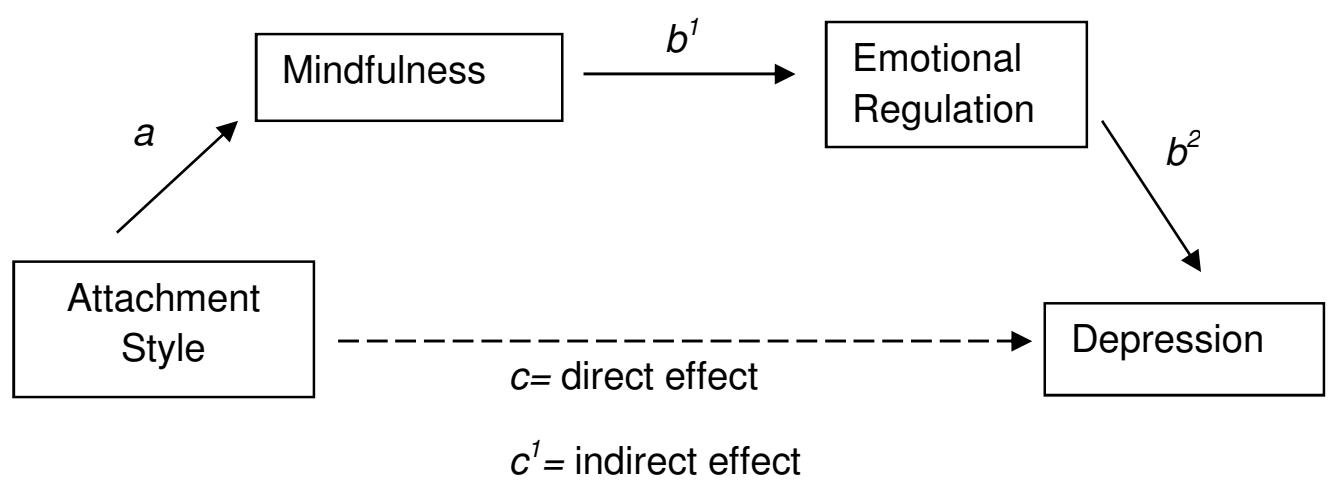


Mindfulness and Emotional Regulation as sequential mediators in the relationship between attachment security and depression

Table 2. Sequential mediation effect of mindfulness and emotional regulation in the relationship between attachment and depression

\begin{tabular}{|c|c|c|c|c|c|c|c|}
\hline \multicolumn{2}{|c|}{ Model Pathways } & \multirow{2}{*}{$\begin{array}{c}\beta \\
3.06\end{array}$} & \multirow{2}{*}{$\begin{array}{l}\text { SE } \\
.80\end{array}$} & \multirow{2}{*}{$\begin{array}{c}t \\
3.83\end{array}$} & \multirow{2}{*}{$\begin{array}{l}p \\
<.001\end{array}$} & \multirow[t]{2}{*}{ LL95\%CI } & \multirow[t]{2}{*}{ UL95\%Cl } \\
\hline Secure & $a$ & & & & & & \\
\hline & $b^{1}$ & .86 & .06 & -14.16 & $<.001$ & & \\
\hline & $b^{2}$ & .31 & .04 & 6.98 & $<.001$ & & \\
\hline & $c$ & -.36 & .33 & -1.12 & .26 & & \\
\hline & $c^{2}$ & .81 & .25 & & & -1.39 & -.39 \\
\hline \multirow[t]{5}{*}{ Preoccupied } & $a$ & -3.42 & .76 & -4.48 & $<.001$ & & \\
\hline & $b^{1}$ & -.85 & .06 & -13.77 & $<.001$ & & \\
\hline & $b^{2}$ & .31 & .04 & 6.91 & $<.001$ & & \\
\hline & $c$ & .33 & .31 & 1.02 & .31 & & \\
\hline & $c^{1}$ & .88 & .27 & & & .44 & 1.51 \\
\hline \multirow[t]{5}{*}{ Dismissive } & $a$ & 1.93 & .84 & 2.31 & $<.05$ & & \\
\hline & $b^{1}$ & -.88 & .06 & -14.80 & $<.001$ & & \\
\hline & $b^{2}$ & .31 & .04 & 7.07 & $<.001$ & & \\
\hline & $c$ & -.35 & .32 & -1.11 & .27 & & \\
\hline & $c^{1}$ & -.52 & .26 & & & -1.14 & -.08 \\
\hline \multirow[t]{5}{*}{ Fearful } & $a$ & -4.72 & .76 & -6.21 & $<.001$ & & \\
\hline & $b^{\prime}$ & -.81 & .06 & -12.59 & $<.001$ & & \\
\hline & $b^{2}$ & .29 & .04 & 6.54 & $<.001$ & & \\
\hline & $c$ & .88 & .36 & 2.46 & .01 & & \\
\hline & $c^{1}$ & 1.09 & .26 & & & .67 & 1.72 \\
\hline
\end{tabular}


Mindfulness and Emotional Regulation as sequential mediators in the relationship between attachment security and depression

The sequential mediating role of mindfulness and emotional regulation (please see Figure 1) was then explored for each of the attachment classifications. Results are provided in Table 2.There was a significant indirect effect of secure attachment on depression through mindfulness and difficulty in emotional regulation, indicating that the process of mindfulness and then difficulty in emotional regulation fully mediates the relationship between secure attachment and depression.

The sequential mediation analysis exploring the relationship between preoccupied attachment and depression also revealed a significant indirect effect through mindfulness and difficulty in emotional regulation, again indicating full mediation.

A partial mediation relationship was indicated in regards to fearful attachment and depression. The total effect was reduced slightly.

According to Hayes (2009) a causal link may still be present despite a seemingly absent association between two variables. Spearman's correlations indicated that dismissive attachment was not associated with depression or mindfulness however the indirect effect was investigated to ensure a significant influence of mindfulness and emotional regulation in the relationship between dismissive attachment and depression was not missed. The mediation analysis revealed a significant association between dismissive attachment and depression. Further there was a significant indirect effect of dismissive attachment on depression through the sequential process of mindfulness and difficulty in emotional regulation, representing full mediation.

Due to truncated variability, further analysis was conducted to explore age and gender as potential confounding factors. The results were largely consistent with the overall findings. 
Mindfulness and Emotional Regulation as sequential mediators in the relationship between attachment security and depression

\section{Discussion}

The aim of the current study was to explore the relationship between attachment styles and depression through the mediators of mindfulness and emotional regulation. The results confirmed previous studies indicating association between the key variables (Goodall, et al., 2012; Pepping, et al., 2014; Siegel, 2007). Further, the analysis revealed that a sequential relationship between mindfulness and emotional regulation fully mediated the relationship between three of the identified attachment styles: secure, preoccupied and dismissive. Dismissive attachment was initially found not to be associated using spearman's correlations with either depression or mindfulness. According to Hayes (2009) the seemingly absent relationship may be explained by the sum of different paths with variables that work in opposing directions, in this example, given the characteristics associated with a dismissive attachment style it would seem reasonable to suggest the use of distraction or distancing strategies. The sequential mediation analysis revealed a significant negative relationship between dismissive attachment and depression that mindfulness and emotional regulation did in fact fully mediate. Interestingly, mindfulness and emotional regulation was only found to play a partial mediation role in the case of fearful attachment. This is potentially reflective of the complexity and severity associated with an individual's history, resulting in this attachment style.

Whilst not included in this study, preliminary analysis was conducted to explore a sequential mediation relationship between attachment style, anxiety and stress, yielding similar effects to depression. These findings further support the role of mindfulness and emotional regulation in ameliorating negative mental health outcomes. We recommend further exploration of this in the future.

Previous research has reported that a negative bias, commonly associated with insecure attachment styles, is significantly related to the increased prevalence of depression (Bowlby, 1980; Roepke \& Seligman, 2015). Defensive exclusion (Bowlby, 1980) effectively limits the 
Mindfulness and Emotional Regulation as sequential mediators in the relationship between attachment security and depression

opportunity to fully process information contrary to beliefs, essentially confirming negative expectations. Conversely, mindfulness awareness and secure attachment, coupled with the development of emotional regulation capacities (Sroufe, 2005) suggests an alternate processing style, where new information is attended to and influences emotional and behavioural outcomes. This alternate path was explored in this study. It was proposed that the initial ability to be mindful in a situation afforded the opportunity for emotional regulation, facilitating an open processing of what is and affecting the outcome of depression. This process was confirmed by the current study. The finding suggests an understanding of the process whereby the impact of insecure attachment styles on cognitive processing can be overridden to ameliorate negative developmental outcomes.

The significance of this lies in understanding the role of internal working models in perpetuating poorer outcomes, even across generations (Alhusen, Hayat, \& Gross, 2013; Burke, 2003) and gives meaning to intervention studies identifying the positive impact of mindfulness on mental health and relationships (Barnes, Brown, Krusemark, Campbell, \& Rogge, 2007; Brown, et al., 2007; Carson, Carson, Gil, \& Baucom, 2007; Shaver, Lavy, Saron, \& Mikulincer, 2007).

\section{Conclusions, limitations and future directions}

To our knowledge this is the first study to explore a sequential processing model that may interrupt the negative cognitive bias associated with insecure attachment and depression. Whilst the results are encouraging, there are several limitations to the study. Firstly, the sample was comprised of first year psychology students with mean scores indicating a moderate level of depression, a further study using a non-university based sample would be beneficial in establishing the generalizability of these results to the wider population.

Secondly, it is unknown from the sample the percentage of participants who were actively engaging in meditation practice. Further, the sample was unevenly distributed in regards to gender and age. Supplementary analysis was largely consistent with the overall findings; 
Mindfulness and Emotional Regulation as sequential mediators in the relationship between attachment security and depression

however given the small male sample it is difficult to draw conclusions regarding a gender effect, thereby representing an area for future research. The cross sectional design of this study limits the ability to derive potential causal links between the variables. However the findings provide a guide for future research, which may include mixed method or longitudinal design, more able to elicit conclusive sequencing of the variables. The inherent difficulty in measuring mindfulness, particularly in a young child creates difficulty in conclusively identifying mindfulness as a mediator between insecure attachment and depression however the commonality established between high mindfulness and secure attachment, as well as an understanding of the balance between the attachment and exploratory system strongly support the hypothesis. Nevertheless the findings suggest an important consideration in developing effective interventions to interrupt the association between negative early care giving and poorer developmental outcomes, such as depression; which represents significant global health, social and economic costs with the potential to cross generations. 
Mindfulness and Emotional Regulation as sequential mediators in the relationship between attachment security and depression

\section{References}

Ainsworth, M. D., Blehar, M. C., Waters, E., \& Wall, S. (1978). Patterns of attachment: a psychological study of the strange situation. Hillsdale, $\mathrm{NJ}$ : Erlbaum.

Alhusen, J. L., Hayat, M. J., \& Gross, D. (2013). A longitudinal study of maternal attachment and infant developmental outcomes. Archives of Women's Mental Health, 1-9.

Baer, R. A., Smith, G. T., Hopkins, J., Krietemeyer, J., \& Toney, L. (2006). Using self report assessments methods to explore facets of mindfulness Assessment 13, 27-45. doi: $10.1177 / 1073191105283504$

Baker, C., Huxley, P., Dennis, M., Islam, S., \& Russell, I. (2015). Alleviating staff stress in care homes for people with dementia: Protocol for stepped-wedge cluster randomised trial to evaluate a web-based Mindfulness- Stress Reduction course. [Article in Press]. BMC Psychiatry. doi: 10.1186/s12888-015-0703-7

Barnes, S., Brown, K. W., Krusemark, E., Campbell, W. K., \& Rogge, R. D. (2007). The role of mindfulness in romantic relationship satisfaction and responses to relationship stress. Journal of Marital and Family Therapy, 33(4), 482-500. Retrieved from http://www.scopus.com/inward/record.url?eid=2-s2.034748833807\&partnerID=40\&md5=9d5175899ccb7bee61236776ddcf7c55

Bartholomew, K., \& Horowitz, L. M. (1991). Attachment Styles Among Young Adults: A Test of a Four-Category Model. Journal of Personality and Social Psychology, 61(2), 226244. Retrieved from

Beck, A. T. (1963). Thinking and Depression: I. Idiosyncratic Content and Cognitive Distortions. Arch Gen Psychiatry, 9(4), 324-333. doi: doi:10.1001/archpsyc.1963.01720160014002.

Bifulco, A., Figueiredo, B., Guedeney, N., Gorman, L. L., Hayes, S., Muzik, M., . . . Henshaw, C. A. (2004). Maternal attachment style and depression associated with childbirth: preliminary results from a European and US cross-cultural study. The British Journal of Psychiatry, 184(46), s31-s37. doi: 10.1192/bjp.184.46.s31

Bowlby, J. (1973). Attachment and Loss: Separation (Vol. 2). New York: Basic Books.

Bowlby, J. (1980). Attachment and Loss: Loss, sadness and depression (Vol. 3). New York: Basic Books.

Bretherton, I., \& Mulholland, K. A. (2008). Internal working models in attachment relationships: elaborating a central construct in attachment theory. In J. Cassidy \& $\mathrm{P}$. R. Shaver (Eds.), Handbook of Attachment: Theory, Research and Clincial Applications (2nd ed., pp. 102-127). New York: Guildford Press.

Brown, K. W., Ryan, R. M., \& Creswell, J. D. (2007). Mindfulness: Theoretical Foundations and evidence for it's salutary effects. Psychological Inquiry, 18, 211-237. Retrieved from doi:10.1080/10478400701598298

Brown, K. W., Ryan, R. M., \& Creswell, J. D. (2008). Beyond me: Mindful responses to social threat. In H. A. Wayment \& J. J. Bauer (Eds.), Transcending Self Interest: Psychological Explorations of the Quiet Ego. Washington: American Psychological Association.

Burke, L. (2003). The impact of maternal depression on familial relationships International Review of Psychiatry, 15, 243-255. Retrieved from doi:10.1080/0954026031000136866

Carson, J. W., Carson, K. M., Gil, K. M., \& Baucom, D. H. (2004). Mindfulness-based relationship enhancement. Behavior Therapy, 35(3), 471-494. Retrieved from http://www.scopus.com/inward/record.url?eid=2-s2.011144224830\&partnerID=40\&md5=b09f7847f45596914a8ac060e8de626d

Carson, J. W., Carson, K. M., Gil, K. M., \& Baucom, D. H. (2007). Self-expansion as a mediator of relationship improvements in a mindfulness intervention Vol. 33. Journal of Marital and Family Therapy (pp. 517-528). Retrieved from 
Mindfulness and Emotional Regulation as sequential mediators in the relationship between attachment security and depression

http://www.scopus.com/inward/record.url?eid=2-s2.035348921702\&partnerlD=40\&md5=27308d94626c6dd4f4b94db15a8dfb80

Cassidy, J. (2008). The nature of the child's ties. In J. Cassidy \& P. R. Shaver (Eds.), Handbook of Attachment: Theory, Research and Clinical Applications (2nd ed., pp. 322). New York: Guildford Press.

Crowell, J. A., Fraley, C. R., \& Shaver, P. R. (2008). Measurement of individual differences in adolescent and adult attachment. In J. Cassidy \& P. R. Shaver (Eds.), Handbook of attachment: Theory, research and clinical application (2nd ed., pp. 599-634). New York: Guildford.

Cummings, E. M., \& Cicchetti, D. (1990). Toward a transactional model of relations between attachment and depression. In M. T. Greenberg, D. Cicchetti \& E. M. Cummings (Eds.), Attachment in the preschool years (pp. 339-372). Chicago: University of Chicago Press.

Dykas, M. J., \& Cassidy, J. (2011). Attachment and the processing of social information across the life span: theory and evidence. Psychological Bulletin, 137(1), 19-46. Retrieved from doi:10.1037/a0021367

Goodall, K., Trejnowska, A., \& Darling, S. (2012). The relationship between dispositional mindfulness, attachment security and emotional regulation. Personality and Individual Differences, 52, 622-626. Retrieved from doi:10.1016/j.paid.2011.12.008

Gratz, K. L., \& Roemer, L. (2004). Multidimensional Assessment of Emotion Regulation and Dysregulation: Development, Factor Structure, and Initial Validation of the Difficulties in Emotion Regulation Scale. Journal of Psychopathology and Behavioral Assessment, 26(1), 41-54. Retrieved from doi:http://dx.doi.org.ezproxy.uow.edu.au/10.1023/B:JOBA.0000007455.08539.94

Hayes, A. F. (2009). Beyond Baron and Kenny: Statistical Mediation Analysis in the New Millennium Communication Monographs, 76(4), 408-420. doi: http://dx.doi.org/10.1080/03637750903310360

Jones, K. C., Welton, S. R., Oliver, T. C., \& Thoburn, J. W. (2011). Mindfulness, spousal attachment, and marital satisfaction: A mediated model. Family Journal, 19(4), 357361. Retrieved from http://www.scopus.com/inward/record.url?eid=2-s2.080053655325\&partnerlD=40\&md5=9d1940c421fd949c8618c82e50f10f21

Kabat-Zinn, J. (2003). Mindfulness-based interventions in context: Past, present, and future. Clinical Psychology: Science and Practice, 10(2), 144-156. Retrieved from http://www.scopus.com/inward/record.url?eid=2-s2.02542438512\&partnerlD=40\&md5=c21ac79ed5e3d860d7b54fe7719585c1

Kessler, R. C., \& Bromet, E. J. (2013). The Epidemiology of Depression Across Cultures. Annu. Rev. Public Health 34, 119-138. doi: 10.1146/annurev-publhealth-031912114409

Lee, J. S., \& Koo, H. J. (2015). The relationship between adult attachment and depression in Korean mothers during the first 2 years postpartum: A moderated mediation model of self-esteem and maternal efficacy. Personality and Individual Differences, 79, 50-56. doi: 10.1016/j.paid.2015.01.021

Lovibond, S. H., \& Lovibond, P. F. (1995). Manual for the Depression Anxiety Stress Scales. Sydney: Psychology Foundation.

Main, M., \& Cassidy, J. (1988). Categories of Response to Reunion With the Parent at Age 6: Predictable From Infant Attachment Classifications and Stable Over a 1-Month Period. Developmental Psychology, 24(3), 415-426. Retrieved from http://www.scopus.com/inward/record.url?eid=2-s2.058149366179\&partnerID=40\&md5=10211c919ab72a49377f13dc102fadca

Mitchell, M., \& Heads, G. (2015). Staying Well: A Follow Up of a 5-Week Mindfulness Based Stress Reduction Programme for a Range of Psychological Issues. [Article]. Community Mental Health Journal, 51(8), 897-902. doi: 10.1007/s10597-014-9825-5 
Mindfulness and Emotional Regulation as sequential mediators in the relationship between attachment security and depression

Murray, C. J. L., \& Lopez, A. D. (Eds.). (1996). The Global Burden of Disease: A Comprehensive Assessment of Mortality and Disability from Diseases, Injuries, and Risk Factors in 1990 and Projected to 2020 Cambridge, MA: : Harvard Univ. Press.

Pepping, C. A., Davis, P. J., \& O'Donovan, A. (2013). Individual differences in attachment and dispositional mindfulness: The mediating role of emotion regulation. Personality and Individual Differences, 54(3), 453-456.

Pepping, C. A., O'Donovan, A., Zimmer-Gembeck, M. J., \& Hanisch, M. (2014). Is emotion regulation the process underlying the relationship between low mindfulness and psychosocial distress? Australian Journal of Psychology, 66(2), 130-138. doi: 10.1111/ajpy. 12050

Reis, S., \& Grenyer, B. F. S. (2004). Fearful attachment, working alliance and treatment response for individuals with major depression. [Article]. Clinical Psychology and Psychotherapy, 11(6), 414-424. doi: 10.1002/cpp.428

Roepke, A. M., \& Seligman, M. E. P. (2015). Depression and prospection. British Journal of Clinical Psychology. doi: 10.1111/bjc. 12087

Schore, A. N. (2001). Effects of a secure attachment relationship on right brain development, affect regulation, and infant mental health. Infant Mental Health Journal, 22(1-2), 7-

66. Retrieved from http://www.scopus.com/inward/record.url?eid=2-s2.00002194118\&partnerID=40\&md5=74710e064d739e938d4218a537c55393

Shaver, P. R., Lavy, S., Saron, C. D., \& Mikulincer, M. (2007). Social foundations of the capacity for mindfulness: An attachment perspective. Psychological Inquiry, 18(4), 264-271. Retrieved from http://www.scopus.com/inward/record.url?eid=2-s2.036349000584\&partnerID=40\&md5=4b68cd73509be8ba41c6155d5af2b120

Siegel, D. J. (2007). The Mindful Brain - Reflection and Attunement in the Cultivation of WellBeing. . New York: W.W. Norton \& Company.

Snyder, R., Shapiro, S., \& Treleaven, D. (2012). Attachment Theory and Mindfulness. Journal of Child and Family Studies, 21(5), 709-717. Retrieved from http://www.scopus.com/inward/record.url?eid=2-s2.084866266599\&partnerlD=40\&md5=cf82bb30a3f72428c88ca281d7c12f0e

Sroufe, L. A. (2005). Attachment and development: A prospective longitudinal study from birth to adulthood. Attachment and Human Development, 7(4), 349-367. Retrieved from doi:10.1080/14616730500365928

Sroufe, L. A., Egeland, B., Carlson, E., \& Collins, W. A. (2005a). The development of the person: The Minnesota study of risk and adaptation from birth to adulthood. New York: Guildford.

Stallman, H. M. (2010). Psychological distress in university students: A comparison with general population data. Australian Psychologist, 45(4), 249-257. doi: 10.1080/00050067.2010.482109

Thorberg, F. A., \& Lyvers, M. (2010). Attachment in relation to affect regulation and interpersonal functioning among substance use disorder in patients. Addiction and Research Theory, 18(4), 464-478. Retrieved from doi:10.3109/16066350903254783 